\title{
The Relationship between Vocabulary Learning Strategies and Vocabulary Proficiency of English Language Learners
}

\author{
F. Filiz Yalçın Tılfarlıoğlu (Corresponding author) \\ Faculty of Education, University of Gaziantep \\ Department of English Language Teaching, Gaziantep 27310, Turkey \\ Tel: 0090-342-360-12-00 E-mail: fyalcin@gantep.edu.tr \\ Yunus Bozgeyik \\ Higher School of Foreign Languages, University of Gaziantep \\ Gaziantep 27310, Turkey \\ Tel: 0090-342-360-15-32Ｅ-mail: yunusbozgeyik@gmail.com
}

Received: 11-05- 2012

doi:10.7575/ijalel.v.1n.2p.91
Accepted: 14-06- 2012

Published: 01-07- 2012

\begin{abstract}
The current study was carried out to examine L2 learners' VLS use habits and the relationship of VLS with their vocabulary proficiency levels. In addition, language learners' beliefs about VLS in terms of usefulness were also studied to understand L2 learners' VLS use habits more deeply. To examine these matters, a descriptive research design was employed. The participants included 252 preparatory students from different proficiency groups (Upper-Intermediate, Intermediate, Pre-Intermediate, Beginner) at Gaziantep University Higher School of Foreign Languages. To collect the related data, they were given "Vocabulary Learning Strategies Questionnaire" and "Vocabulary Levels Test". The data analyses were conducted by descriptive and inferential statistics. The results of the study showed that the participants used a wide range of VLS, and there was an overlap between their beliefs about VLS in terms of usefulness and how often they used them to a large extent. Secondly, Memory Strategies correlated positively with the participants' academic and general vocabulary proficiency levels. However, there were also some differences among the proficiency groups about which specific VLS are correlated with their vocabulary proficiency levels. As to the regression analysis results, none of the VLS predicted participants' vocabulary proficiency levels.
\end{abstract}

Keywords: Vocabulary learning strategies, vocabulary proficiency, learner beliefs

\section{Introduction}

Very broadly, lexical knowledge can be defined as the knowledge of the spoken or written form of a given word, its meaning and morphology. In a detailed description, two concepts, receptive and productive vocabulary knowledge, deepen the complexity of vocabulary knowledge further. It contains a wide range of components such as being able to retrieve the correct word for productive use and the right meaning for receptive use, being aware of various relations between words and being able to select appropriate words taking into consideration the degree of formality.

There are some concepts which are closely related to vocabulary knowledge. The foremost of them is the distinction between grammatical words and lexical words. Grammatical words have little or no semantic content of their own, and they specify grammatical relations. On the other hand, lexical words convey a meaning. Carter (1998) explains this distinction stating that:

The former (grammatical words) comprises a small and finite class of words which includes pronouns (I, you, me), articles (the, a), auxiliary verbs (must, could, shall), prepositions (in, on, with, by) and conjunctions (and, but). Grammatical words like this are also variously known as 'functional words', 'functors', 'empty words'. Lexical words, on the other hand- which are also variously known as 'full 


\section{나교 \\ International Journal of Applied Linguistics \& English Literature \\ ISSN 2200-3592 (Print), ISSN 2200-3452 (Online)}

Vol. 1 No. 2; July 2012

words' or' 'content words' -include nouns (man, cat), adjectives (large, beautiful), verbs (find, wish) and adverbs (brightly, luckily) (p. 8).

Depth and breadth of vocabulary knowledge, which have attracted a great deal of attention in the field, refer to two contrasting terms. Vocabulary breadth is a quantitative term, and it can be defined as the number of words known by a person. On the other hand, vocabulary depth is a qualitative term, and it is about the knowledge of different aspects of a word such as "its meaning (to several levels of precision), its grammatical categories, its derivations, its pragmatic and sociolinguistic value, and its collocations" (Schoonen and Verhallen, 2008, p. 212).

The example given by Graves (1986) can be great help here in understanding the nature of vocabulary breadth and depth development. According to Graves (1986, p. 54):

Children may at first learn only the feature "four-legged" for dog, and will overgeneralize the word's meaning, using dog to refer to all four-legged animals until they acquire additional features. In this view, the development of meaning proceeds in an orderly fashion, becoming increasingly fuller and more precise.

It is logical to believe that lexical items are not stored in human mind in an unorganized way. If vocabulary knowledge is organized in some way or other, cognitive load can be minimized in a way that would allow language learners to store more words efficiently. This fact is explained by Aitchison (2003, p. 5) in a succinct manner:

Words cannot be heaped up randomly in the mind for two reasons. First, there are so many of them. Second, they can be found so fast. Psychologists have shown the human memory is both flexible and extendable, provided that the information is structured. Random factors and figures are extremely difficult to remember, but enormous quantities of data can be remembered and utilized, as well as they are well organized.

The view that lexical items are not stored randomly has forced researchers to come up with models which attempt to describe how lexical items are stored in human mind. The foremost of these models have been put forward by Collins and Quillian (1969), Collins and Loftus (1975), and Bock and Levelt (1994). All these models are similar to each other in that "the organization of the lexicon is set up as a semantic network of interconnected elements" (Carroll, 2008, p. 110).

The knowledge about the vocabulary size of native speakers may have practical implications for language teachers by giving them an idea about how many words a language learner should know to achieve an acceptable level of proficiency in a given language. About this matter, Goulden, Nation and Read (1990) claim that university graduate native speakers know about 20000 word families which include root words, and their inflectional and derivational forms, and they acquire this amount of vocabulary by adding very roughly 1.000 words families each year to their lexical store consisting of 4000-5000 word families when they are five years old. However, it seems that this amount of vocabulary is hard to attain by language learners even if there can be rare examples of it.

On the other side, learning difficulty may arise from the characteristics of language learners such as their language proficiency and motivation levels or from the characteristics of the target words. In terms of the difficulties posed by word characteristics, Nation (2001, p. 23) claims that "the more a word represents patterns and knowledge that learners are already familiar with, the lighter its learning burden". In addition to the degree of similarity between the vocabularies of two languages, other factors can also play role in determining the degree of vocabulary learning difficulties.

In terms of teaching vocabulary, a number of methods for vocabulary teaching have changed through the history and each method has brought with itself a different outlook as to how vocabulary should be taught. It is inevitable that each of these methods has its own advantages and disadvantages. Language learners develop a wide range of beliefs about themselves and different aspects of language learning. Victori and Lockhart (1995, p. 224) defines learner beliefs as "general assumptions that students hold about themselves as learners, about factors influencing language learning and about the nature of language learning and teaching." Bernat and Lloyd (2007) put forward that the effect of learner beliefs on language proficiency can be explained directly through an analysis of how they govern the use of learning strategies. According to them, "students can have 'mistaken', uninformed or negative beliefs, which may lead to a reliance on less effective strategies, resulting in a negative attitude towards learning and autonomy, classroom anxiety, and poor cognitive performance" (Bernat and Lloyd, 2007, p. 79).

Page $\mid 92$ 


\section{(1) \\ International Journal of Applied Linguistics \& English Literature \\ ISSN 2200-3592 (Print), ISSN 2200-3452 (Online)}

Vol. 1 No. 2; July 2012

Developed to teach, Vocabulary Learning Strategies (VLS) can be defined very broadly as actions taken by the language learners in order to foster vocabulary learning in the target language. Hamzah (2009: 42) explains VLS and their characteristics in the following manner:

It is possible to view a vocabulary learning strategy from at least three different angles. First, a vocabulary learning strategy, very broadly speaking, could be any action taken by the learner to aid the learning process of new vocabulary. Whenever a learner needs to study words, he/she uses strategy/strategies to do it. Second, a vocabulary learning strategy could be related to only such actions which improve the efficiency of vocabulary learning. Hence, there are actions which learners might employ but which do not enhance the learning process - a perfectly possible scenario with poor learners. Third, a vocabulary learning strategy might be connected to conscious (as opposed to unconscious) actions taken by the learner in order to study new words.

Schmitt's (1997) taxonomy divides all the vocabulary learning strategies into two as discovery strategies and consolidation strategies. Discovery strategies are those which are helpful for discovering the meaning of the unknown words. On the other hand, consolidation strategies help language learners to store and remember the meaning and other aspects of words such as their spelling, pronunciation etc. after discovering their meaning. There are also subdivisions of these divisions.

Discovery strategies consist of determination and social strategies. Schmitt (1997) describes the former strategies as:

If learners do not know a word, they must discover its meaning by guessing from their structural knowledge of the language, guessing from L1 cognate, guessing from context, using reference materials, or asking someone else. Determination strategies facilitate gaining knowledge of a new word from the first four options (p. 210)

As an important sample of determination strategies, word part strategy involves discerning the word in terms of its root an done or more suffixes. Nation (2001, p. 278) summarizes the necessary knowledge and the two steps to perform word-part strategy in the following manner:

1: Breaking the unknown word into pairs. This step requires learners to be able to recognize prefixes and suffixes when they occur in words.

2: Relating meaning of the word parts to the meaning of the word. This step requires learners to know the meanings of the common word parts. It also requires learners to be able to re-express the dictionary definition of a word to include the meaning of its prefix and, if possible, its stem and suffix.

In terms of another useful tool, using dictionaries, Marckwardt (1973, p. 396) explains the aspects of dictionaries in the following manner:

The utility of the dictionary as a reliable source for word meanings, spelling, and pronunciation is widely recognized. A good dictionary also contains information about grammar, usage status, synonym discrimination, application of derivative affixes, and distinctions between spoken and written English not generally treated in text-books, even in a rudimentary fashion.

Actually, vocabulary is thought to be learned more easily from context. Sternberg's (1987, p. 90) explanation of the matter provides an example of this thinking:

Most vocabulary is learned from context. During the course of one's lifespan, one is exposed to innumerable words through seemingly countless sources-textbooks, lectures, newspapers, magazines, friends, enemies, parents, movies, and so on. Even if the one learned a small proportion of the words thus encountered in contexts, in which they are presented, one could possibly develop a vocabulary of tens of thousands of words, which represents only an infinitesimal proportion of our exposure to words.

Cognate is another strategy for learning vocabulary meaning to share the same origin for a word between two languages. Hakan (2006) claims that the value of cross-linguistically similar words such as cognates is questionable in terms of vocabulary learning for productive skills, even if they can facilitate language learners' comprehension skills. According to him:

Cross-linguistically similar words, which form the central part of the learner's potential vocabulary, facilitate the learner's task in comprehension, but not at all to the same extent in production. The learner

Page $\mid 93$ 


\section{(4) \\ International Journal of Applied Linguistics \& English Literature \\ ISSN 2200-3592 (Print), ISSN 2200-3452 (Online)}

Vol. 1 No. 2; July 2012

will not use L2 items productively until they, or parts of them, have been learned, but the potential knowledge across languages perceived to be similar is used for comprehension before learning has taken place. Existing knowledge structures are activated by incoming data, all the more so if cross-linguistic or other formal similarities can be established, as they can in comprehension of closely related language (Hakan, 2006, p. 24).

Schmitt (1997, p. 210) explains the social strategies in the following manner:

A second way to discover a new meaning employs the social strategy of asking someone who knows. Teachers are often in this position, and they can be asked to give help in a variety of ways: giving the L1 translation if they know it, giving a synonym, giving a definition by paraphrase, using new word in a sentence, or any combination of these.

On the other hand, consolidation strategies include memory strategies (mnemonics) including those actions learners make use of in order to facilitate retention of the unknown words (Sanaoui, 1995). Cognitive strategies including repetition of the words through writing and saying them aloud or silently, using word cards and word list. Also, metacognitive strategies are related with language learners' managing their own vocabulary development, assessing their vocabulary development through various means such as vocabulary tests and taking the necessary measures if the outcomes do not meet their expectations (Barcroft, 2009).

New words can be learned with the help of pictures. Al-Seghayer (2001) claims that the contribution of visual stimuli to vocabulary learning can also be attributed to a specific process which links verbal system of human beings to their imagery system, and this process is closely related with the organization of linguistic knowledge and imagery system in our minds. He describes this process stating that: "Learners of a second language have two separate verbal systems (L1 and L2) and a common imagery system. There is a suggestion that the translation of words via simultaneous verbal and visual presentations would not only link the two verbal systems, but that this storage in the second verbal system would also have an additional effect on learning" (Al-Seghayer, 2001, p. 205).

Moreover, getting benefit from the related words, new vocabulary are learned through linking new words to other words in the target language. Sheng, McGregor and Marian (2006, p. 573) state that:

A parallel developmental phenomenon, the syntagmatic-paradigmatic shift, is observed in children's responses in word association tasks. At age 5, most children respond to a word stimulus with a word that follows in a syntactic sequence (e.g., cold- outside). By age 9, most children respond with a word from the same form class or paradigm (e.g., cold-hot). Researchers consequently termed responses from different form classes syntagmatic and those from the same class paradigmatic. A predominance of paradigmatic over syntagmatic responses is indicative of a more developed semantic system, as this pattern is typical of mature language users.

Another Memory Strategy which language learners employ while learning new vocabulary is semantic mapping. Stahl and Vancil (1986, p. 62) describe this strategy in the following way:

In semantic mapping, a teacher chooses a keyword and other target words from the material that the students will read. The keyword is listed on the board and students are asked to suggest terms associated with the key word. The teacher writes the suggested words in a list on the board as the students suggest them. From this list, a map is constructed. The relationships between the keyword and suggested words are discussed thoroughly. Students are then asked to categorize each section of the map.

Learners can consolidate their vocabulary knowledge by paying attention to written or spoken form of words. Schmitt (1997, p. 214) explains how this Memory strategy can be made use of in the following way: "One can explicitly study the spelling or pronunciation of a word. Other options are to visualize the orthographical form of a word in an attempt to remember it, or to make mental representation of the sounds of a word, perhaps making use of rhyming words."

In terms of social aspect of vocabulary learning, Slavin (1996) claims that the value of the cooperative learning may be directly attributed to the discussion environment created by it: "Interaction among students on learning tasks will lead in itself to improved student achievement. Students will learn from one another because in their discussions of the content, cognitive conflicts will arise, inadequate reasoning will be exposed, disequilibration will occur, and higher-quality understandings will emerge" (Slavin, 1996, p. 1161).

Page $\mid 94$ 


\section{(1) \\ International Journal of Applied Linguistics \& English Literature \\ ISSN 2200-3592 (Print), ISSN 2200-3452 (Online)}

Vol. 1 No. 2; July 2012

According to Schmitt (1997), cognitive strategies are similar to memory strategies in many aspects. The main difference between them is that "they are not focused so specifically on manipulative mental processing" (Schmitt, 1997, p. 215). Metacognitive Strategies of vocabulary learning on the other hand, are related with language learners' managing their own vocabulary development, assessing their vocabulary development through various means such as vocabulary tests and taking the necessary measures if the outcomes don't meet their expectations (Barcroft, 2009).

Gu and Johnson (1996) examined the VLS used by language learners and then correlated the findings of this analysis with participants' vocabulary size and English proficiency. The results of the correlations showed that positive correlations existed between vocabulary size and self initiation strategies (e.g. finding out personally relevant and interesting vocabulary), activation strategies (e.g. deliberately using words that had been studied), selective attention (e.g. knowing which words should be given attention to), dictionary look up strategies, meaning oriented note taking strategies (e.g. writing down meanings and synonyms of the target words). Visual repetition (e.g. memorizing spelling and writing the word repeatedly) correlated with vocabulary size negatively. In general, strategies which include rote-memorization or paying attention to formal characteristics of target words didn't correlate significantly with vocabulary size.

\section{Method}

The aim of the current study was to examine vocabulary learning strategy (VLS) use habits of preparatory students at Gaziantep University Higher School of Foreign Languages, and students' beliefs about VLS in terms of usefulness. The study also aimed to find out whether there were any relationships between VLS and students' vocabulary proficiency. In order to achieve these aims, the study employed a descriptive research design. The data was collected through measurable instruments.

\subsection{Participants}

The participants in the study included 252 preparatory students at Gaziantep University Higher School of Foreign Languages. There were 1296 students at the school in 2009-2010 academic year and the participants were selected from the population using random sampling methods. They were mostly 17-18 years old, and they were from four different English proficiency levels (Upper-Intermediate, Intermediate, Pre-Intermediate and Beginner).

The participants were allocated to different proficiency levels according to the results of a placement test which was administered at the beginning of the academic year by the school and assumed as reliable. The proportion of the participants in each proficiency level is approximately the same. Of the participants $63(25 \%)$ were Upper-Intermediate, $63(25 \%)$ were Intermediate, $62(24.6 \%)$ were Pre-Intermediate and $64(25.4 \%)$ were Beginner-Level English language learners.

\subsection{Instruments}

In order to carry out the research two instruments were used. The first instrument was Vocabulary Learning Strategies Questionnaire (VLSQ) developed by Sener (2003). The second one was Vocabulary Levels Test (VLT) which was developed by Nation (1990) and adapted by Ekmekci (1999).

\subsection{Data Collection and Data Analysis Procedure}

Piloting procedure was undertaken to examine how much time was needed to complete the instruments and whether the items in the instruments posed any comprehension problems on the part of the participants. Another aim of the pilot study was to examine the reliability of the instruments.

The reliability analysis with Cronbach's Alpha showed that both of the instruments were reliable (.889 for VLSQ and .891 for VLT). VLT and VLSQ were administered in the spring semester of 2009-2010 academic year. In accordance with the aims of the study, VLT sheets were numbered by the teachers of each class so that the researcher could match the results obtained from this instrument for each participant with those from VLSQ.

The procedures for the administration of the VLSQ were same. The data collected by means of the instruments were examined by using SPSS 15. To assess VLS use habits of the participants and their beliefs about these strategies in terms of usefulness, the mean scores for participants' responses to VLSQ were calculated for each item both for frequency and usefulness scales at the first step. 


\section{International Journal of Applied Linguistics \& English Literature \\ ISSN 2200-3592 (Print), ISSN 2200-3452 (Online)}

Vol. 1 No. 2; July 2012

\section{Results and Discussion}

As can be seen in Table 1, the most often used VLS by the participants was "writing down new vocabulary" $(\mathrm{M}=3.88)$. This finding shows us that there was a strong affinity among the participants for learning new vocabulary through writing them down.

Table 1. Means and standard deviations for the most often used VLS

\begin{tabular}{|c|c|c|c|c|}
\hline No & Strategy & $\begin{array}{l}\text { Strategy } \\
\text { Category }\end{array}$ & M & $\mathrm{SD}$ \\
\hline 61 & When I learn new words in the class, I write them anywhere available. & $\mathrm{COG}$ & 3.88 & 1.21 \\
\hline 40 & $\begin{array}{l}\text { When I read or hear the explanation of a word, I remember the word I } \\
\text { have learned before. }\end{array}$ & MEM & 3.79 & 1.02 \\
\hline 9 & $\begin{array}{l}\text { If I do not know the word in a written text, I try to guess the meaning } \\
\text { of it from the surrounding sentences }\end{array}$ & DET & 3.75 & .98 \\
\hline 2 & $\begin{array}{l}\text { When I do not know the meaning of a word, I use a bilingual } \\
\text { dictionary. }\end{array}$ & DET & 3.71 & 1.00 \\
\hline 63 & $\begin{array}{l}\text { I pay attention to the words of native speakers when I speak with } \\
\text { them }\end{array}$ & MET & 3.64 & 1.25 \\
\hline
\end{tabular}

As to the VLS which were believed to be the most useful, Table 2 shows that participants believed that "guessing the meaning" of new vocabulary from context $(\mathrm{M}=2.83)$ and "writing down new vocabulary" $(\mathrm{M}=2.82)$ were the two most useful strategies.

Table 2. Means and standard deviations for the VLS believed to be most useful

\begin{tabular}{|c|c|c|c|c|}
\hline No & Strategy & $\begin{array}{l}\text { Strategy } \\
\text { Category }\end{array}$ & M & SD \\
\hline 9 & $\begin{array}{l}\text { If I do not know the word in a written text, I try to guess the meaning of } \\
\text { it from the surrounding sentences }\end{array}$ & DET & 2.83 & .44 \\
\hline 61 & When I learn new words in the class, I write them anywhere available & $\mathrm{COG}$ & 2.82 & .47 \\
\hline 62 & I do exercises in the special vocabulary sections of the text books. & $\mathrm{COG}$ & 2.76 & .53 \\
\hline 36 & $\begin{array}{l}\text { If the words take place in phrasal verbs, I learn these phrasal verbs, too. } \\
\text { (e.g. take } \rightarrow \text { take on, take off, take up) }\end{array}$ & MEM & 2.75 & .52 \\
\hline 63 & I pay attention to the words of native speakers when I speak with them & MET & 2.75 & .51 \\
\hline
\end{tabular}

On the contrary, keeping a diary in English was the least often used VLS among the participants $(\mathrm{M}=1.29)$. The reason for this can be attributed to the fact that keeping a diary in English requires relatively higher-level of English proficiency, and the participants were not proficient enough to make use of this strategy when the study was conducted. In terms of their belief on which strategy was least effective, participants thought that using semantic grids was the least useful strategy $(\mathrm{M}=1.86)$. This strategy was followed by writing words in particular shapes $(\mathrm{M}=1.97)$.

More analyses were conducted to get a picture of the participants' VLS use habits and their beliefs about these strategies in terms of usefulness on item basis.

Page $\mid 96$ 


\section{International Journal of Applied Linguistics \& English Literature}

ISSN 2200-3592 (Print), ISSN 2200-3452 (Online)

Vol. 1 No. 2; July 2012

Table 3. Means and standard deviations for the scores of participants in

VLS categories with regards to frequency of use

\begin{tabular}{llll}
\hline & $\mathrm{N}$ & $\mathrm{M}$ & $\mathrm{SD}$ \\
\hline Determination & 252 & 3.25 & .49 \\
Metacognitive & 252 & 2.82 & .71 \\
Memory & 252 & 2.76 & .54 \\
Cognitive & 252 & 2.51 & .64 \\
Social/Dis & 252 & 2.46 & .60 \\
Social/Con & 252 & 2.23 & .92 \\
Valid & 252 & & \\
\hline
\end{tabular}

According to the scores of the participants for VLS categories, it is crystal clear that Determination Strategies were the most often used VLS category among others $(M=3.25)$. It is interesting to note that the least often used strategies among the participants were Social/Discovery and Social/Consolidation Strategies, which entail cooperative learning (Slavin, 1996).

At the second step, mean scores of participants for each VLS category were calculated with regards to frequency and usefulness scales, and several one-way ANOVA tests were run on these mean scores by taking VLS categories as independent and the mean scores for frequency of use and usefulness scales as dependant variable.

Table 4. One-way ANOVA results for the mean scores in different VLS categories with regards to frequency

\begin{tabular}{llllll}
\hline & $\begin{array}{l}\text { Sum of } \\
\text { Squares }\end{array}$ & Df & Mean Square & F & p \\
\hline Between Groups & 157.98 & 5 & 31.60 & 71.47 & .000 \\
Within Groups & 665.82 & 1506 & .44 & & \\
Total & 823.80 & 1511 & & & \\
\hline
\end{tabular}

The results summarized in Table 4. shows that there were significant differences among the mean scores of students in six VLS categories $(\mathrm{p}=.000,<.05)$.

The pairwise comparisons between strategy categories in terms of their frequency of use show that Determination Strategies have significantly higher mean scores than Social/Discovery (.79, p=.000), Social/Consolidation (1.02, p=.000), Memory (.50, p=.000), Cognitive (.74, p=.000), and Metacognitive Strategies (.43, $\mathrm{p}=.000)$. In other words, participants used Determination Strategies significantly more often than other VLS.

Pairwise comparisons for the usefulness mean scores between VLS categories put forward fewer significant differences than those for frequency of use. This means that participants' beliefs about VLS categories in terms of usefulness did not differentiated from each other as much as their frequency of use.

Additionally, Determination Strategies have the highest mean score $(\mathrm{M}=2.57)$ in terms of participants beliefs about them with regards to usefulness. To put it differently, participants believed that Determination Strategies were the most useful VLS among others in terms of their contribution to vocabulary proficiency.

Before examining the relationship between VLS and participants' vocabulary proficiency, it is of importance to get a picture of participants' vocabulary proficiency in order to make more reliable inferences. To achieve this aim, mean scores of the four proficiency groups (Upper-Intermediate, Intermediate, Pre-Intermediate, Beginner) in the Vocabulary Levels Test (VLT) were calculated for 2000, 3000, 5000, University and 10000-levels.

The mean scores in five levels and overall of the VLT decreases in parallel with the decrease in the proficiency levels of participants. In all of the levels and overall of the VLT, Upper-Intermediate group got the highest mean scores $(M=12.27$ in 2000; $M=11.32$ in 3000; $M=8.87$ in 5000; $M=9.24$ in University; $M=3.22$ in 10000 ; $\mathrm{M}=44.90$ in Total). After Upper-

Intermediate, Intermediate group came with the second highest mean scores (M=10.79 in 2000; $M=9.62$ in 3000 ; Page $\mid 97$ 
International Journal of Applied Linguistics \& English Literature

ISSN 2200-3592 (Print), ISSN 2200-3452 (Online)

Vol. 1 No. 2; July 2012

$\mathrm{M}=5.71$ in 5000; $\mathrm{M}=5.11$ in University, $\mathrm{M}=2.32$ in 10000 levels and $\mathrm{M}=33.59$ in Total). Intermediate group was followed by Pre- Intermediate $(M=8.84$ in 2000; $M=5.68$ in 3000; $M=3.95$ in 5000; $M=3.76$ in University; $\mathrm{M}=1.13$ in 10000 and $\mathrm{M}=23.34$ in Total) and Beginner groups $(\mathrm{M}=7.69$ in $2000 ; \mathrm{M}=4.38$ in $3000 ; \mathrm{M}=3.83$ in 5000; $\mathrm{M}=2.73$ in University; $\mathrm{M}=1.09$ in 10000 and $\mathrm{M}=19.73$ in Total).

Namely, there was a parallelism between the proficiency levels of participants and their mean scores at different levels and overall of VLT. In other words, higher proficiency groups got higher mean scores, and lower proficiency groups got lower scores in VLT. When the mean scores for all of the participants in VLT are examined, it is clear that the mean scores of the participants decrease in parallel to the increase in the levels of the VLT (at 2000 level: $M=9.89$; at 3000 level: $M=7.74$; at 5000 level $M=5.59$; at 10000: 1.94). This makes sense from the point of the fact that higher levels of the VLT include lower-frequency words, i.e., more "difficult" words.

Pearson correlation test was applied to examine the relationships between VLS and participants' vocabulary proficiency.

Table 5. Correlations between vocabulary proficiency and VLS for all of the participants

\begin{tabular}{llcccccc}
\hline & & TWO & THREE & FIVE & UNIV. & TEN & TOTAL \\
& & & & & & & .071 \\
DETERMINATION & Pearson Correlation & .085 & .023 & .048 & .088 & .047 & .071 \\
& Sig. (2-tailed) & .180 & .716 & .450 & .166 & .458 & .261 \\
& $\mathrm{~N}$ & 252 & 252 & 252 & 252 & 252 & 252 \\
SOCIAL/DIS & Pearson Correlation & .014 & .011 & .002 & .046 & -.064 & .010 \\
& Sig. (2-tailed) & .822 & .864 & .981 & .464 & .312 & .874 \\
& $\mathrm{~N}$ & 252 & 252 & 252 & 252 & 252 & 252 \\
SOCIAL/CON & Pearson Correlation & .079 & .054 & -.056 & .046 & -.041 & .026 \\
& Sig. (2-tailed) & .211 & .391 & .373 & .471 & .516 & .681 \\
MEMORY & $\mathrm{N}$ & 252 & 252 & 252 & 252 & 252 & 252 \\
& Pearson Correlation & .107 & .108 & .071 & $.145\left(^{*}\right)$ & .093 & $.133\left(^{*}\right)$ \\
& Sig. (2-tailed) & .091 & .088 & .264 & .021 & .142 & .035 \\
COGNITIVE & $\mathrm{N}$ & 252 & 252 & 252 & 252 & 252 & 252 \\
& Pearson Correlation & .019 & .018 & .010 & .043 & -.041 & .017 \\
& Sig. (2-tailed) & .769 & .776 & .875 & .498 & .521 & .792 \\
& $\mathrm{~N}$ & 252 & 252 & 252 & 252 & 252 & 252 \\
METACOGNITIVE & Pearson Correlation & .085 & .081 & .067 & .120 & .009 & .096 \\
& Sig. (2-tailed) & .180 & .200 & .290 & .057 & .886 & .127 \\
& $\mathrm{~N}$ & 252 & 252 & 252 & 252 & 252 & 252 \\
\hline & & & & & &
\end{tabular}

** Correlation is significant at the 0.01 level (2-tailed).

*Correlation is significant at the 0.05 level (2-tailed).

Note: Univ.: University

The correlation analysis results summarized in Table 5 pointed out two significant correlations between VLT scores and VLS categories when the data for all of the participants were included in the correlation analyses. According to the correlation results, Memory Strategies correlated positively both with participants' mean scores at University level $(\mathrm{r}=.141, \mathrm{p}<.05)$ and overall VLT scores $(\mathrm{r}=.126, \mathrm{p}<.05)$. To put it differently, as participants used Memory Strategies more, their scores at University Level and overall of the VLT tended to increase significantly.

Furthermore, correlations between Vocabulary Proficiency and VLS for the Upper-Intermediate Group were analyzed putting forward six significant correlations. The first positive correlation was found between the scores of participants at 3000 level, which includes high frequency words, and Metacognitive Strategies $(r=.291, p<.05)$. The correlation of the University level mean scores with VLS gave positive correlations for Memory $(\mathrm{r}=. .253$, $\mathrm{p}<.05)$, Cognitive $(.348, \mathrm{p}<.01)$ and Metacognitive Strategies $(\mathrm{r}=.347, \mathrm{p}<.01)$. Lastly, the overall VLT scores correlated positively with Cognitive $(r=.272, \mathrm{p}<.05)$ and Metacognitive Strategies $(r=.290, \mathrm{p}<.05)$. 


\section{나교 \\ International Journal of Applied Linguistics \& English Literature \\ ISSN 2200-3592 (Print), ISSN 2200-3452 (Online)}

Vol. 1 No. 2; July 2012

The review the correlation results for the Upper-Intermediate group puts forward that vocabulary proficiency of the Upper-Intermediate group in high frequency words (3000 level words) increased significantly as the participants in this group used Metacognitive Strategies more.

There aren't any significant correlations between the scores of the Intermediate group in VLT and any of the VLS categories. This shows us that decrease or increase of use in any VLS categories isn't parallel to the decrease or increase of scores in VLT significantly.

The correlation results for the Pre-Intermediate group point to two significant and positive correlations. The first of them was found between the groups' mean scores in University level and Metacognitive Strategies ( $\mathrm{r}=.314$, $\mathrm{p}<.05)$. To remember, Metacognitive Strategies correlated with the University level mean scores of the Upper-Intermediate group as well. The other positive correlation was found between overall VLT mean scores and Determination Strategies $(r=.278, \mathrm{p}<.05)$.

The correlation analyses for the Beginner group indicated only one significant and positive correlation between Metacognitive Strategies and VLT scores at 2000 level, which consists of high-frequency words $(r=.265, \mathrm{p}<.05)$.

As a result, Metacognitive Strategies positively correlated with high frequency words (2000 and 3000 level words) both for the Upper-Intermediate and Beginner groups. This means that increase in the use of Metacognitive Strategies brought about a significant increase in high-frequency vocabulary proficiency for these groups which had very different language proficiency levels. Metacognitive Strategies also correlated positively with University level words for Upper and Pre-Intermediate groups. This points to the fact that Metacognitive Strategies contributed to the "academic" vocabulary proficiency of the related groups significantly.

Correlation results also pointed out a number of differences among proficiency groups. For example, the scores of the Upper-Intermediate group at University level correlated with Memory, Cognitive and Metacognitive Strategies altogether. However, University level mean scores correlated positively only with Metacognitive strategies for the Pre-Intermediate group.

Another thing to be noted, which was referred before, is the fact that the efficiency of VLS or combinations of VLS can change according to the type of vocabulary proficiency we are dealing with (Fan, 2003) as can exemplified by the correlation results for the Upper-Intermediate group.

As to the multiple regression test results, they indicated that none of the VLS categories predicted vocabulary proficiency for any of the proficiency groups.

\section{Conclusion}

The current study found out that the participants employed a wide variety of VLS in different percentages, and their VLS use habits and beliefs about these strategies in terms of usefulness followed a similar pattern. The regression test results showed none of the VLS categories predicted VLT scores of our participants. However, the correlation results between VLS categories and VLT scores show some significant and positive correlations. When the correlation tests were run for all of the participants without separating them according to their language proficiency levels, it was clear that Memory Strategies positively correlated both with University level and overall VLT scores and these types of strategies which are mostly about language learners' managing their own vocabulary development through different means such as creating opportunities to learn vocabulary, checking their own vocabulary development, were found to be related with high frequency and "academic" vocabulary proficiency across different proficiency groups. This means that the increase in the use of Memory Strategies brought about a significant increase in "academic" and general vocabulary proficiency. When the correlation tests were run for each proficiency group separately, it was found that Metacognitive Strategies correlated positively with low-frequency vocabulary proficiency (2000 and 3000 level) and "academic" vocabulary proficiency (University level) for different language proficiency groups. In addition to that, these strategies correlated positively with general vocabulary proficiency for high-level language learners (Upper-Intermediate). The results also showed that language proficiency and the type of vocabulary proficiency (academic, low-frequency etc.) were two factors which had an effect on the effectiveness of VLS.

\subsection{Pedagogical Implications}

The findings of the current research and discussion of these findings presented in the preceding sections might provide language teachers and learners alike with some valuable suggestions in terms of current vocabulary learning and teaching practices.

To remember, memory strategies positively correlated with University-level and overall VLT scores when the 


\section{나교 \\ International Journal of Applied Linguistics \& English Literature \\ ISSN 2200-3592 (Print), ISSN 2200-3452 (Online)}

Vol. 1 No. 2; July 2012

correlation tests were run for all of the participants. Taking into consideration, the fact that the participants in the current study were from a wide range of language proficiency levels from beginner to upper intermediate, we can claim that memory strategies were found to be related with "academic" and general vocabulary proficiency for language learners of different proficiency levels. In this context, memory strategies seem very valuable especially for language classrooms comprised of students from different proficiency levels. In such classrooms, English teachers may contribute to "academic" and general vocabulary proficiency of their students by training them on memory strategies and giving place to vocabulary learning activities which allow them to use these strategies because as the study by Torun (2010) suggests through these means L2 learners' making use of certain VLS can be ensured.

Another pattern that was observed from the examination of the correlation results is the fact that metacognitive strategies, which are mostly about language learners' managing their own vocabulary development through different means such as creating opportunities to learn vocabulary, checking their own vocabulary development, were found to be related with high frequency and "academic" vocabulary proficiency across different proficiency groups. Besides, metocognitive strategies were also found to be related with general vocabulary proficiency for high-level learners (upper-intermediate). If we take into the consideration the fact that the value of metacognitive strategies is also verified in the field by lots of studies (Rasekh and Ranjbary, 2003; Zhao, 2009 etc.), we can claim that these strategies may provide language learners a good opportunity for developing their high frequency, "academic" and general vocabulary proficiency. English teachers may help their students to employ these strategies by informing them about the values of metacognitive strategies and raising positive beliefs for these strategies as it can be seen in preceding sections that there was a harmony between how useful the participants believed the VLS to be and how often they used them to a large extent.

It is also inferred that the answer to which VLS contribute to the general vocabulary proficiency of language learners significantly can change according to language proficiency of learners. The review of correlation results between general vocabulary proficiency and VLS categories in the preceding sections justified this claim. To exemplify, determination strategies correlated positively with overall VLT scores of the upper-intermediate group correlated with cognitive and metacognitive strategies. The practical implication here is that English teachers should take into consideration language proficiency of their students while deciding on which VLS they will encourage among their students because the effectiveness of VLS in terms of their contribution to vocabulary proficiency may change according to language proficiency of learners.

Lastly, correlation results for each proficiency group also implied that vocabulary proficiency at different levels (2000-5000, University etc.) and general vocabulary proficiency should be handled differently as it is also suggested by Fan's (2003) study. For example, the correlation analyses for the upper-intermediate group showed that metacognitive strategies were related with vocabulary proficiency at 3000 level. On the other hand, correlations for the same group pointed out a significant relation between University-level vocabulary proficiency and memory, cognitive and metacognitive strategies. The existence of a similar pattern for the pre-intermediate group points out the necessity for language learners to choose VLS they will employ taking into consideration which kind of vocabulary (high-frequency, low-frequency, academic etc.) they will handle. At this point, teachers have great responsibility in helping their students to choose the right kind of strategies which are in accordance with their specific vocabulary learning goals.

\section{References}

Aitchison, J. (2003). Words in the Mind: An Introduction to the Mental Lexicon. Blackwell Publishing, Malden.

Al-Seghayer, K. (2001). The effect of multimedia annotation modes on L2 vocabulary acquisition: A Comparative Study. Language Learning and Technology. 5(1), 202-232.

Barcroft, J. (2009). Strategies and performance in intentional L2 vocabulary learning. Language Awareness, 18(1), 74-89.

Bernat, E. and Lloyd, R. (2007). Exploring the gender effect on efl learners' beliefs about language learning. Australian Journal of Educational \& Developmental Psychology. 7, 79-91.

Bock, J.K. and Levelt, W. (1994). Language production: grammatical encoding. In Handbook of Psycholinguistics, Gernsbacher, M.A. (Ed.). Academic Press, San Diego. pp. 945-984.

Carroll, D. (2008). Psychology of language. Thomson Wadsworth, Belmont. 


\section{International Journal of Applied Linguistics \& English Literature}

ISSN 2200-3592 (Print), ISSN 2200-3452 (Online)

Vol. 1 No. 2; July 2012

Carter, R. (1998). Vocabulary: Applied linguistic perspectives. Routledge, London.

Collins, A.M. and Loftus, E.F. (1975). A spreading activation theory of semantic processing. Psychological Review, 82, 407-428.

Collins, A.M. and Quillian, M.R. (1969). Retrieval time from semantic memory. Journal of Verbal Learning and Verbal Bahaviour, 8, 240-247.

Ekmekci, N. M. (1999). Vocabulary learning strategies and their effect on turkish EFL learners outcomes. Master's Thesis, Eskisehir Anadolu University, Eskisehir.

Fan, M.Y. (2003). Frequency of use, perceived usefulness, and actual usefulness of second language vocabulary. The Modern Language Journal, 87(2), 222-241.

Goulden, R., Nation, P., and Read, J. (1990). How large can a receptive vocabulary be? Applied Linguistics, 11, 341-363.

Graves, M. (1986). Vocabulary learning and instruction. Review of Research in Education. 13, 49-89.

Gu, Y. and Johnson, R.K. (1996). Vocabulary learning strategies and language learning outcomes. Language Learning Journal, 46(4), 643-679.

Hakan, R. (2006). Cross-linguistic similarity in foreign language learning. Multilingual Matters Limited, Clevedon.

Hamzah, M.S.G., Kafipour, R., and Abdullah, S.K. (2009). Vocabulary learning strategies of Iranian undergraduate EFL students and its relation to their vocabulary size. European Journal of Social Sciences, 11(1), 39-50.

Marckwardt, A.H. (1973). The dictionary as an English teaching resource. TESOL Quarterly, 7(4), 369-379.

Nation, P. (1990). Teaching and learning vocabulary. Heinle and Heinle: Boston.

Nation, P. (2001). Learning vocabulary in another language. Cambridge University Press: Cambridge.

Rasekh, Z.E. and Ranjbary, R. (2003). Metacognitive strategy training for vocabulary learning. TESL-EJ, 7(2), $1-15$

Sanaoui, R. (1995). Adult learners' approaches to learning vocabulary in second languages. The Modern Language Journal, 79(1), 15-28.

Schmitt, N. (1997). Vocabulary learning strategies. In Schmitt, N. and McCarthy, M. (Ed.). Vocabulary: Description, acquisition and pedagogy (199-228). Cambridge University Press, Cambridge.

Sheng, Li., McGregor, K.K. and Marian, V. (2006). Lexical-semantic organization in bilingual children: Evidence from a repeated word association task. Journal of Speech, Language, and Hearing Research, 49(3), 572-587.

Schoonen, R. and Verhallen, M. (2008). The assessment of deep word knowledge in young first and second language learners. Language Testing, 25(2), 211-236.

Sener, S. (2003). The relationship between vocabulary learning strategies and vocabulary size of Turkish EFL students. Unpublished M. A. Thesis, Canakkale Onsekiz Mart University. Canakkale.

Slavin, R. E. (1987). Developmental and motivational perspectives on cooperative learning: a reconciliation. child development, 58(5). Special Issue on Schools and Development: 1161-1167.

Stahl, S.A., and Vancil, S.J. (1986) Discussion is what makes semantic maps work. The Reading Teacher, 40, 62-67.

Sternberg, R.J. (1987) Most vocabulary is learnt from context. In McKeown and Curtis M.E. (Eds.). The nature of vocabulary learning (89-106). Lawrence Erlbaum Associates Inc., New Jersey

Torun, Y.E. (2010). The effects of strategy training on vocabulary development. Master's Thesis, University of Gaziantep, Gaziantep

Victori, M. and Lockhart, W. (1995). Enhancing metacognition in self-directed language learning. System, 23(2), 223-234.

Zhao, N. (2009) An experimental study on the effects of different reading tasks on L2 vocabulary acquisition. English Language Teaching Journal, 2(3), 69-79.

Page $\mid 101$ 